\title{
Modeling of atmospheric primary radioclimatic variables in Nigeria for microwave radio propagation applications
}

\author{
S. E. Falodun ${ }^{1}$. J. S. Ojo ${ }^{1}$ (I) S. T. Aboyeji ${ }^{1}$
}

Received: 14 October 2020 / Accepted: 5 January 2021 / Published online: 11 January 2021

(c) The Author(s) 2021 OPEN

\begin{abstract}
As modern technology advances, more of the radio communication systems are adopting microwave and millimeter waves' spectral. However, the effects of meteorological parameters over the radio communication signal operating at microwave and millimeter waves have been the concern of radio engineers. Determination of radio refractivity requires as input meteorological parameters such as temperature, humidity, and atmospheric pressure. To assess the level of degradation due to atmospheric parameters, the ability to easily measure these meteorological parameters is important in planning a good quality radio communication networks. In this study, five (5) years (2013-2017) satellite-based meteorological parameters comprising air temperature, relative humidity, and pressure were obtained from the European Center for Medium-Range Weather Forecast (ECMWF) at four synopsis hours of the day (00:00 LT, 00:06 LT, 12 noon LT, and 18:00 LT) on daily basis to model the required radio climatic variables in Nigeria. The data were obtained for 26 locations based on the four climatic regions in Nigeria. Multiple regression analysis of the data was performed and coefficients $\left(b_{0^{\prime}}\right.$ $b_{1}, \ldots, b_{6}$ ) were obtained to effectively predict the monthly temperature, pressure, and relative humidity at the surface level. Eight stations were used for validation; two each from the four climatic regions of Nigeria based on the coefficient of determination $\left(R^{2}\right)$, mean absolute error (MAE), and root mean square error (RMSE). The meteorological parameters were compared based on the multiple regression analysis (MRA) and the modified interpolation techniques (Kriging and Inverse Distance-IDW). The three methods show nearly good accuracy in the prediction, however, the MRA was found to have a better prediction for the meteorological parameter in Nigeria. Hence, in predicting the refractive index parameters using MRA, the allowed RMSEs for temperature, pressure, and relative humidity are $0.559,4.693$, and 0.267 , respectively. Likewise, the allowed MAEs for temperature pressure and relative humidity are $0.492,0.229$, and 3.837, respectively.
\end{abstract}

Keywords Meteorological parameters $\cdot$ Multiple regression analysis $\cdot$ Kriging $\cdot$ Inverse distance weighting $\cdot$ Nigeria

\section{Introduction}

Climatological data of high spatial resolution are largely available in most developed countries, based on the network of such stations but getting such data in many other regions of the world may be difficult and creating larger gaps [1]. The management and maintenance of gauge stations to obtain reliable data can be very expensive and problematic [2]. The availability of meteorological data for the measurement of important parameters can be tasking especially in the tropical region. Any modeling and prediction need adequate data to develop and verify the model. Historical data in the region are either not available or are in media that make them not accessible. It is not unusual to find that most of the data in the National Meteorological/ Hydrological services in Africa are kept on paper. Such papers are easily damaged and a lot of data lost. Some

$\triangle$ J. S. Ojo, ojojs_74@futa.edu.ng; S. E. Falodun, sefaldun@futa.edu.ng; S.T. Aboyeji, aboyejisunday97@gmail.com|'Department of Physics, Federal University of Technology, Akure, Nigeria. 
of the historical data are also kept on compact discs and recently on flash drives which can easily be damaged. Hence, interpolation methods are important tools to solve these challenges and to improve the database which are indispensable for climatological research [1]. Ground station datasets are difficult to get in most of the locations where the meteorological stations are not available majorly due to the high cost of purchase, installation, and maintenance of weather instruments. Therefore, many locations in the tropical regions, Nigeria inclusive may have difficulty in obtaining their meteorological parameters. Among such parameters that are considered in this study are temperature, pressure, and relative humidity which very important in the radio communication field for the determination of radio refractivity. The radio refractivity is one of the major factors needed for characterizing microwave radio communication link of a particular location.

The forecasting of severe weather and extreme climate events is one of the major challenges facing meteorological services worldwide and more so in the tropics [3]. There are a number of deterministic and geostatistical interpolation approaches that are responsible for the estimation of the needed parameters for no-observed space between sampling locations [4]. Amongst some of the techniques that have been employed to predict rainfall in East Africa include the use of numerical and statistical methods. Spatial interpolation atmospheric parameters have been performed using machine learning algorithms [5]. [6] compared different spatial interpolation methods, which also include hybrid methods, and suggested that the kriging approach gives a better result. Mathematical functions especially polynomial regressions have also been used to characterize weather parameters including rainfall in different parts of the world. For instance, [7] used polynomial regression to derive a simple model for the monthly climate variable to relate climate to position and elevation on Digital Elevation Model (DEM) in Ireland. Accuracy assessments with subsets of each climate data set showed that polynomial regression can predict average monthly climate in Ireland with mean absolute errors of 5-15 mm for monthly precipitation, $0.2-0.5^{\circ} \mathrm{C}$ for monthly averaged maximum and minimum temperature, and 6-15 $\mathrm{min}$ for monthly averaged sunshine hours in Ireland. Commonly used spatial interpolation methods for the prediction of atmospheric parameters in addition to the ones used in this study are Spline and trend surface methods. However, the spline method is mostly used in a dense population of sample points and not suitable for sparse and finite sample points [17]. Also, the trend surface method depends more on the existing spatial distribution trend of interpolation elements [18]. Hence, the choice of Kriging, inverse distance weighting, and multiple linear regressions in this study are based on their accuracy and correlation to each other.

Nigeria is located in the Tropics, where the climate is seasonally damp and very humid. Nigeria is affected by four climate types; these climate types are distinguishable, as one moves from the southern part of the country to the northern part of Nigeria through Nigeria's middle belt. The climates are the Sub-Sahelian, Mid-Land, Guinea Savannah, and Coastal. Changes in these climates can be noticed as one moves from one location to another in the country. To enhance the prediction of the severe weather conditions and the performance of microwave radio wave signals in most locations in Nigeria, in which the needed meteorological data may not be available. It is therefore imperative to model equations for predicting atmospheric weather parameters (temperature, relative humidity, and pressure), to high accuracy.

Multiple polynomial regressions analysis method was used to examine the relationship and establish a model between several independent variables and a dependent variable (criterion variable). Regression analysis involves identifying the relationship between a dependent variable and one or more independent variable and is of the most important statistical tools which are extensively used for data analysis [8].

This study aims to develop predictive models using multiple polynomial regression analysis for the time-series values of temperature, pressure, and relative humidity. The meteorological predictions from the multiple regression approach were compared with the result of Kriging and Inverse Distance Weighting.

\section{Theoretical background}

This section presents some theoretical background related to the subject matter. Some of the related metric measures were also discussed.

\subsection{Radioclimatic variables}

The most important primary Radioclimatic variables that influence microwave radio communication links are temperature, relative humidity, and pressure. Normally these meteorological parameters vary due to the dispersion and transport of gases and particles in the lower atmosphere (Troposphere). The characterization and the structure of geographical locations play an important role in modeling the primary Radioclimatic variables. The troposphere is an essential part of the atmosphere where radio communication links traverse. The temperature in the troposphere decreases with the increasing altitude $[9,10]$. Therefore, warm air near the surface of the earth can rapidly rise 
replacing the cold denser air at the upper part of the atmosphere. The pressure depends on the value of temperature and for every $350 \mathrm{~m}$ of the altitude above the sea level atmospheric pressure in the troposphere drops by about $33.86 \mathrm{hPa}$. The gravity of the earth holds the atmosphere close to the surface, so the density and pressure of air decrease as the altitude increases. Relative humidity also varies with space and time.

\subsection{Kriging}

Kriging, synonymous with geostatistical interpolation, began in the mining industry as a means of bettering ore reserve estimation in the early 1950s [11]. Ordinary Kriging is one of the most basic of Kriging methods. It provides an estimate at an unobserved location of variable $z$, based on the weighted average of adjacent observed sites within a given area.

The theory is derived from that of regionalized variables as reported in [12] and can be described by considering the function $Z\left(s_{\mathrm{i}}\right)$ where $\mathrm{s}_{\mathrm{i}}$ represent all the sample locations, $i=1,2, \ldots, n$. An expression for the unsampled location by considering the weighted average using ordinary kriging is:

$z\left(s_{o}\right)=\sum_{i=1}^{n} \lambda_{i} z\left(s_{i}\right)$

where $\lambda_{i}$ are the weights assigned to each of the observed samples.

The weights are usually summed to unity so that the predictors provide an unbiased estimation.

$\sum_{i=1}^{n} \lambda_{i}=1$

The weights are calculated from the matrix equation:

$\lambda=A^{-1} b$

where $A=\mathrm{zA}$ matrix of semi variances between the data points, $b$ is a vector of estimated semi variances between the data points and the points at which the variable $z$ is to be predicted, and $\lambda$ is the resulting weights.

\subsection{Inverse distance weighting (IDW)}

IDW is one of the interpolation techniques, and it is based on the assumption that objects that are closer to one another are more alike than those that are farther apart.

The weight of each sample point is inverse proportional to the distance. IDW is given by:
$Z_{o}=\frac{\sum_{i=1}^{N} z_{i} d_{i}^{-n}}{\sum_{i=1}^{N} d_{i}^{-n}}$

where, $Z_{o}$ is the unknown point, di is the distance to the known point, $z_{i}$ is the value of the known point, and $n$ is the total number of predictions for each validation case.

\subsection{Multiple regression analysis}

Linear regression analysis is a statistical tool by which a line is fitted through a set of experimental data using the least-squares method. Regression is used in a wide variety of applications to analyze how a single dependent variable is affected by the values of one or more independent variables [13].

The polynomial models can be used in those situations where the relationship between study and explanatory (independent) variables is curvilinear. Sometimes a nonlinear relationship in a small range of explanatory variables can also be modeled by polynomials.

The model is said to be linear when it is linear in parameters, such as:

$y=\beta_{o}+\beta_{1} x+\beta_{2} x^{2}+\varepsilon$

and

$y=\beta_{o}+\beta_{1} x_{1}+\beta_{2} x_{2}+\beta_{3} x_{1}^{2}+\beta_{4} x_{2}^{2}+\beta_{5} x_{1} x_{2}+\varepsilon$

Equations (5) and (6) are the second-order polynomial equations in one and two variables, respectively. by:

The kth order polynomial model in one variable is given

$y=\beta_{o}+\beta_{1} x+\beta_{2} x^{2}+\ldots+\beta_{k} x^{k}+\varepsilon$

If $x_{j}=x^{j}, j=1,2, \ldots, k$, then the model is a multiple linear regressions model just like Eq. (5) where the additional variable $x_{2}$ added.

\section{Materials and method adopted}

\subsection{Datasets and sites}

Five (5) years (2013-2017) of satellite re-analyzed meteorological data comprising air temperature, relative humidity, and pressure were obtained from European Center for Medium-Range Weather Forecast (ECMWF) at four synopsis hours of the day, namely 00:00 LT, 00:06 LT, 12:00 LT, and 18:00 LT on daily basis. The data were obtained at a resolution of $0.25^{\circ} \times 0.25^{\circ}$ for 26 locations in the Nigeria region spanning $0^{\circ} \mathrm{W}$ to $15^{\circ} \mathrm{E}$ and $15^{\circ} \mathrm{N}$ to $0^{\circ} \mathrm{S}$. The key stations 
were selected from each climate region, namely six from Sub-Sahelian (SS), seven from Mid-land (ML), eight from Guinea Savannah (GS), and five from the Coastal region (C). Figure 1 is a map of Nigeria depicting the locations, while Table 1 shows the features of the climatic region of the studied locations.

\subsection{Model development}

The 36 climate models ( 3 climate variables $\times 12$ months) were developed through polynomial regression, by relating climate to site coordinates and elevations.

Fig. 1 Map of Nigeria showing study locations

Table 1 Characteristics of the climatic regions of the studied location

\begin{tabular}{|c|c|c|c|c|c|}
\hline $\mathrm{S} / \mathrm{N}$ & Site & Latitude $\left({ }^{\circ} \mathrm{E}\right)$ & Longitude ( $\left.{ }^{\circ} \mathrm{W}\right)$ & Elevation (m) & Climate region \\
\hline 1 & Sokoto & 13.07 & 5.23 & 284.88 & Sub-Sahelian \\
\hline 2 & Kastina & 12.98 & 7.62 & 513.33 & Sub-Sahelian \\
\hline 3 & Gusau & 12.16 & 6.68 & 452.93 & Sub-Sahelian \\
\hline 4 & Kano & 12.00 & 8.59 & 469.38 & Sub-Sahelian \\
\hline 5 & Gashua & 12.88 & 11.03 & 338.24 & Sub-Sahelian \\
\hline 6 & Maiduguri & 11.83 & 13.15 & 324.75 & Sub-Sahelian \\
\hline 7 & Bida & 9.08 & 6.01 & 123.08 & Mid-Land \\
\hline 8 & Abuja & 9.07 & 7.48 & 475.95 & Mid-Land \\
\hline 9 & Jos & 9.90 & 8.86 & 1264.50 & Mid-Land \\
\hline 10 & Lafia & 8.51 & 8.52 & 204.66 & Mid-Land \\
\hline 11 & Bauchi & 10.30 & 9.82 & 600.10 & Mid-Land \\
\hline 12 & Kumo & 10.04 & 11.22 & 417.84 & Mid-Land \\
\hline 13 & Jimeta & 9.25 & 12.45 & 191.67 & Mid-Land \\
\hline 14 & Saki & 8.67 & 3.39 & 471.19 & Guinea Savannah \\
\hline 15 & Ibadan & 7.38 & 3.95 & 225.16 & Guinea Savannah \\
\hline 16 & Abeokuta & 7.15 & 3.36 & 56.82 & Guinea Savannah \\
\hline 17 & Ado-Ekiti & 7.61 & 5.24 & 430.54 & Guinea Savannah \\
\hline 18 & Akure & 7.26 & 5.21 & 346.17 & Guinea Savannah \\
\hline 19 & Lokoja & 7.82 & 6.75 & 37.65 & Guinea Savannah \\
\hline 20 & Enugu & 6.46 & 7.55 & 151.91 & Guinea Savannah \\
\hline 21 & Oshodi & 6.54 & 3.31 & 24.78 & Guinea Savannah \\
\hline 22 & Sapele & 5.88 & 5.69 & 7.64 & Coastal \\
\hline 23 & Owerri & 5.48 & 7.04 & 72.48 & Coastal \\
\hline 24 & Port Harcourt & 4.82 & 7.05 & 5.00 & Coastal \\
\hline 25 & Calabar & 4.98 & 8.34 & 57.11 & Coastal \\
\hline 26 & Warri & 5.55 & 5.79 & 6.42 & Coastal \\
\hline
\end{tabular}

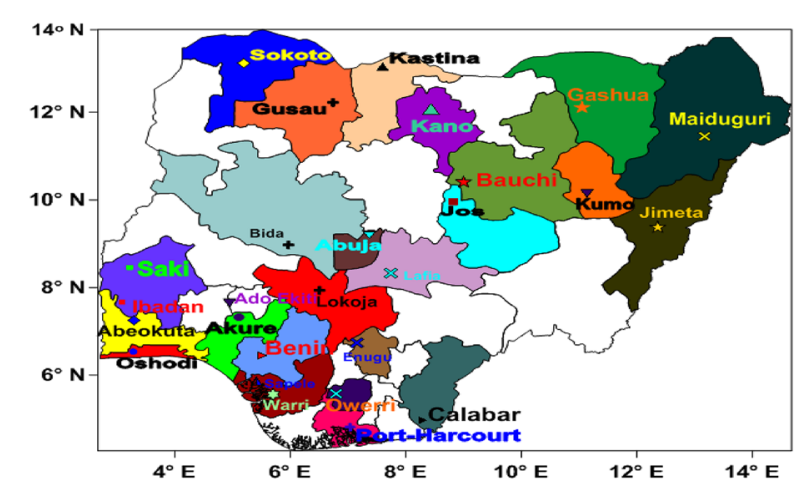


Each of the 36 climate models takes the form:

Values of meteorological parameter $(\mathrm{VMP})=b_{0}+b_{1}$ lat. $+b_{2}$ long. $+b_{3}$ lat. $^{2}+b_{4}$ long. $^{2}+b_{5}$ lat. $\times$ long.

$$
+b_{6} \text { elevation }
$$

where meteorological parameters are temperature in ${ }^{\circ} \mathrm{C}$, relative humidity in \%, or pressure in $\mathrm{hPa}$. Longitude and latitude in degrees, elevation of the location in meter, $b_{0}$ to $b_{6}$ are coefficients to be determined with multiple polynomial regression analysis.

\subsection{Accuracy assessment}

Radioclimatic variables (temperature, relative humidity, and pressure) were also obtained for eight (8) locations (Table 2) for the validation assessment. These data were selected for even distribution over Nigeria's climate by picking two stations each for each of the climatic zones. These validation sites (Table 2) are different from the initial datasets used for model generation. The coefficients obtained from the multiple polynomial regression models for the 26 locations were used to predict the climate values for the selected eight locations. Kriging and inverse distance weighting were also used to assess the accuracy of the multiple polynomial regression analysis. The observed and the predicted values of the two interpolation methods were compared with the multiple polynomial regression analysis.

\subsection{Statistical evaluation}

The various metric measures used for modeling the Radioclimatic variables in this study are the mean absolute error (MAE), coefficient of determination $\left(R^{2}\right)$ and root mean square error (RMSE).

\subsubsection{Mean absolute error (MAE)}

The MAE of the polynomial regression of equations can be obtained as:

Table 2 Features of the sites used in the validation

\begin{tabular}{lccc}
\hline Site & Latitude $\left({ }^{\circ} \mathrm{E}\right)$ & Longitude $\left({ }^{\circ} \mathrm{W}\right)$ & Elevation $(\mathrm{m})$ \\
\hline Wawa & 0.41 & 9.90 & 261.54 \\
Minna & 6.55 & 9.58 & 250.60 \\
Makurdi & 8.54 & 7.73 & 91.23 \\
Bali & 10.96 & 7.85 & 202.82 \\
Ikeja & 3.35 & 6.60 & 35.33 \\
Ikom & 8.72 & 5.96 & 99.98 \\
Nguru & 10.46 & 12.88 & 348.31 \\
Bama & 13.69 & 11.52 & 328.26 \\
\hline
\end{tabular}

$M A E=\frac{1}{n} \sum_{i=1}^{n}\left|P_{i}-O_{i}\right|$

where $P_{i}=$ the predicted value at the point $\left(\right.$ long $_{i}$, lat $\left._{i}\right)$, $O_{i}=$ the observed (measured) value at the point.

$\left(\right.$ long $_{i}$, lat $\left._{i}\right)$, and $\mathrm{n}=$ the number of points.

\subsubsection{Coefficient of determination $\left(\mathrm{R}^{2}\right)$}

The coefficient of determination has used in this study was obtained from the model using the formula:

$R^{2}=\frac{\text { MSS }}{\text { TSS }}=\frac{\text { TSS }- \text { RSS }}{\text { TSS }}$

where MSS is the model sum of squares which is the sum of the square of the prediction from the linear regression model minus the mean for that variable. TSS is the total sum of squares which is associated with the outcome variable (It is the sum of the square minus their mean), and RSS is the residual sum of squares- It is the sum of squares of the observations minus the prediction from the mean.

\subsubsection{Root mean square error (RMSE)}

Root mean square error (RMSE) can be described as the standard deviation of the residual error (predictors). The error as used in this study is given as:

$\mathrm{RMSE}=\sqrt{\frac{\sum_{i=1}^{n}\left(\hat{y}-y_{i}\right)^{2}}{n}}$

where $y_{i}$ is the observed value for each of the observations, and $\widehat{y}_{i}$ is the predicted value for each of the observations.

\section{Results and discussion}

Figure 2 shows the average climate pattern for temperature, relative humidity, and pressure (2013-2017) in Nigeria. Generally, the relative humidity has more seasonal variability than temperature and pressure. This can also be confirmed from the high standard deviation obtained for relative humidity than the two other variables. The maximum relative humidity value of $91.24 \%$ was obtained in August while the minimum average value of $27.23 \%$ 


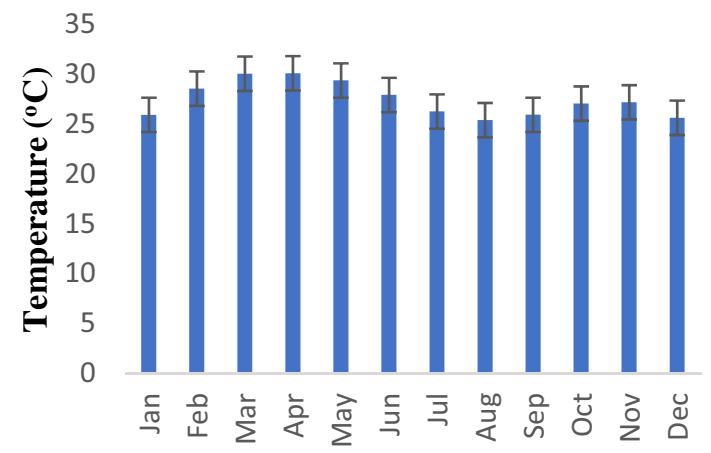

(a)

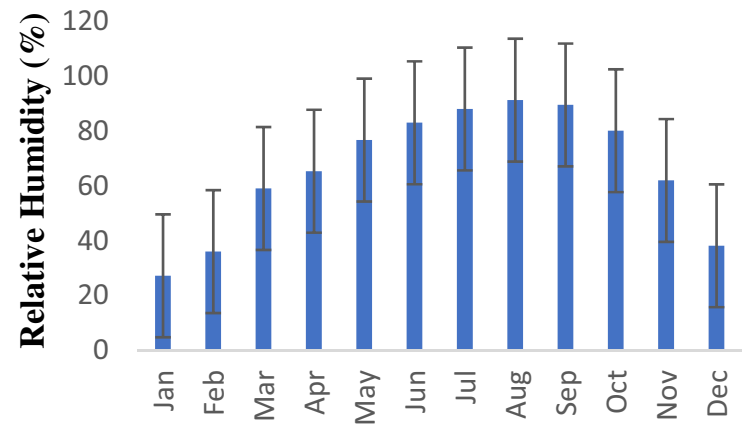

(b)

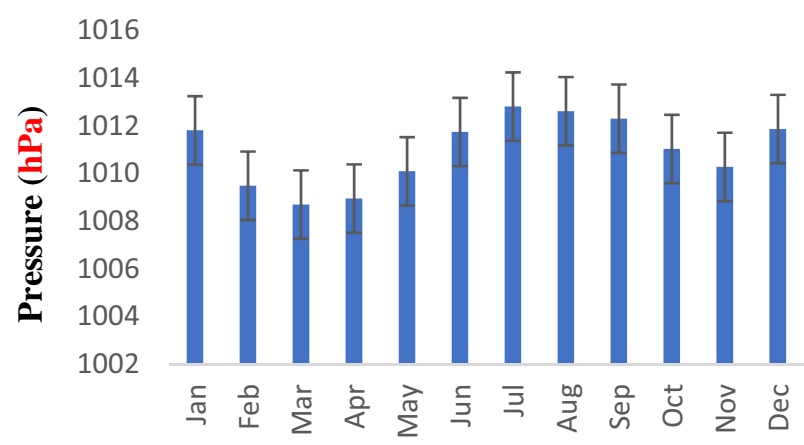

(c)

Fig. 2 Average monthly climate pattern for a temperature, b relative humidity and $\mathbf{c}$ pressure with their standard deviation for Nigeria between 2013 and 2017

occurred in January across Nigeria. Temperature does not have more seasonal variability as compared to relative humidity. The standard deviation of temperature can be observed to be the lowest. The maximum temperature value of about $30.06{ }^{\circ} \mathrm{C}$ occurred in April while the average minimum value of about $25.37^{\circ} \mathrm{C}$ was recorded in August. The pressure values can be observed to oscillate seasonally with a high value in January decreases gradually till

Table 3 Coefficients for temperature obtained from polynomial regression analysis

\begin{tabular}{|c|c|c|c|c|c|c|c|c|c|c|}
\hline \multicolumn{11}{|c|}{ TEMPERATURE } \\
\hline \multicolumn{11}{|c|}{ Coefficients } \\
\hline Months & Const. bo & Lat. b1 & Long. b2 & Lat. $^{2}$ b3 & Long. ${ }^{2}$ b4 & Lat.X Long. b5 & Elev. b6 & $\mathrm{R}^{2}$ & Adj. $R^{2}$ & Standard Error \\
\hline Jan & 20.68 & 1.863 & 0.144 & -0.099 & 0.009 & -0.058 & -0.003 & 0.912 & 0.885 & 0.745 \\
\hline Feb & 17.67 & 2.773 & 0.008 & -0.126 & 0.029 & -0.069 & -0.003 & 0.788 & 0.721 & 0.779 \\
\hline Mar & 19.19 & 2.175 & -0.457 & -0.064 & 0.061 & -0.049 & -0.002 & 0.855 & 0.810 & 0.771 \\
\hline Apr & 23.78 & 0.997 & -0.601 & -0.000 & 0.056 & -0.019 & -0.003 & 0.938 & 0.919 & 0.636 \\
\hline May & 29.51 & -0.435 & -0.847 & 0.067 & 0.046 & 0.027 & -0.003 & 0.974 & 0.966 & 0.481 \\
\hline Jun & 31.51 & -1.042 & -0.964 & 0.080 & 0.029 & 0.067 & -0.003 & 0.970 & 0.961 & 0.484 \\
\hline Jul & 28.70 & -0.489 & -0.784 & 0.040 & 0.020 & 0.053 & -0.003 & 0.953 & 0.939 & 0.401 \\
\hline Aug & 27.02 & -0.279 & -0.446 & 0.021 & 0.004 & 0.040 & -0.003 & 0.921 & 0.896 & 0.342 \\
\hline Sept & 30.20 & -0.794 & -0.795 & 0.048 & 0.012 & 0.064 & -0.003 & 0.956 & 0.942 & 0.346 \\
\hline Oct & 29.21 & -0.353 & -0.908 & 0.042 & 0.040 & 0.031 & -0.003 & 0.951 & 0.936 & 0.416 \\
\hline Nov & 23.39 & 1.383 & -0.688 & -0.049 & 0.053 & -0.026 & -0.003 & 0.808 & 0.748 & 0.567 \\
\hline Dec & 22.76 & 1.640 & -0.387 & -0.086 & 0.035 & -0.042 & -0.003 & 0.909 & 0.880 & 0.655 \\
\hline
\end{tabular}


Table 4 Coefficients for relative humidity obtained from polynomial regression analysis

RELATIVE HUMIDITY

\begin{tabular}{|c|c|c|c|c|c|c|c|c|c|c|}
\hline \multicolumn{11}{|c|}{ Coefficients } \\
\hline Months & Const. bo & Lat. b1 & Long. b2 & lat. $^{2}$ b3 & long. ${ }^{2}$ b4 & Lat. X Long. b5 & Elev. b6 & $\mathrm{R}^{2}$ & Adj. $R^{2}$ & Standard Error \\
\hline Jan & 151.260 & -13.873 & 0.869 & 0.144 & -0.311 & 0.219 & -0.018 & 0.927 & 0.903 & 10.112 \\
\hline Feb & 156.130 & -8.375 & -1.744 & -0.278 & -0.392 & 0.462 & -0.024 & 0.962 & 0.950 & 8.154 \\
\hline Mar & 48.110 & 12.897 & 4.638 & -1.184 & -0.339 & -0.151 & -0.008 & 0.972 & 0.963 & 5.936 \\
\hline Apr & 47.460 & 11.500 & 4.951 & -0.841 & -0.153 & -0.517 & -0.001 & 0.983 & 0.977 & 3.624 \\
\hline May & 49.620 & 9.482 & 4.625 & -0.549 & -0.016 & -0.612 & 0.004 & 0.982 & 0.977 & 2.302 \\
\hline Jun & 75.570 & 4.014 & 2.939 & -0.288 & -0.061 & -0.304 & 0.004 & 0.971 & 0.963 & 1.971 \\
\hline Jul & 88.120 & 0.933 & 2.025 & -0.107 & -0.058 & -0.157 & 0.004 & 0.963 & 0.951 & 1.322 \\
\hline Aug & 93.010 & -0.379 & 1.204 & 0.003 & -0.004 & -0.118 & 0.003 & 0.907 & 0.878 & 1.030 \\
\hline Sept & 83.500 & 2.078 & 1.789 & -0.110 & 0.026 & -0.260 & 0.003 & 0.956 & 0.942 & 1.199 \\
\hline Oct & 32.760 & 14.502 & 3.966 & -0.790 & 0.142 & -0.743 & 0.000 & 0.984 & 0.980 & 2.222 \\
\hline Nov & 85.400 & 6.651 & 1.227 & -0.829 & -0.195 & -0.043 & -0.013 & 0.977 & 0.970 & 4.985 \\
\hline Dec & 167.680 & -12.780 & -3.501 & 0.085 & -0.072 & 0.286 & -0.017 & 0.955 & 0.941 & 7.355 \\
\hline
\end{tabular}

Table 5 Coefficients for pressure obtained from polynomial regression analysis

\begin{tabular}{|c|c|c|c|c|c|c|c|c|c|c|}
\hline \multicolumn{11}{|l|}{ Pressure } \\
\hline \multicolumn{11}{|c|}{ Coefficients } \\
\hline Months & Const. bo & Lat. b1 & Long. b2 & lat. $^{2}$ b3 & long. ${ }^{2}$ b4 & Lat.X Long. b5 & Elev. b6 & $\mathrm{R}^{2}$ & Adj. $R^{2}$ & Standard Error \\
\hline Jan & 1016.15 & -1.222 & -0.310 & 0.070 & 0.002 & 0.035 & 0.001 & 0.952 & 0.937 & 0.325 \\
\hline Feb & 1016.51 & -1.576 & -0.195 & 0.075 & -0.013 & 0.040 & 0.001 & 0.882 & 0.845 & 0.283 \\
\hline Mar & 1013.51 & -0.790 & 0.157 & 0.018 & -0.030 & 0.019 & 0.001 & 0.932 & 0.911 & 0.299 \\
\hline Apr & 1011.27 & -0.210 & 0.274 & -0.010 & -0.028 & 0.002 & 0.001 & 0.965 & 0.953 & 0.256 \\
\hline May & 1009.06 & 0.525 & 0.400 & -0.042 & -0.019 & -0.028 & 0.001 & 0.983 & 0.977 & 0.203 \\
\hline June & 1010.10 & 0.610 & 0.491 & -0.044 & -0.017 & -0.038 & 0.001 & 0.983 & 0.978 & 0.206 \\
\hline July & 1012.32 & 0.347 & 0.320 & -0.028 & -0.011 & -0.028 & 0.001 & 0.978 & 0.971 & 0.185 \\
\hline Aug & 1012.56 & 0.166 & 0.244 & -0.015 & -0.008 & -0.021 & 0.001 & 0.969 & 0.959 & 0.162 \\
\hline Sept & 1011.48 & 0.286 & 0.310 & -0.019 & -0.009 & -0.027 & 0.001 & 0.976 & 0.969 & 0.142 \\
\hline Oct & 1011.78 & -0.002 & 0.218 & -0.009 & -0.015 & -0.009 & 0.001 & 0.972 & 0.963 & 0.150 \\
\hline Nov & 1015.58 & -1.159 & -0.043 & 0.050 & -0.020 & 0.032 & 0.001 & 0.859 & 0.814 & 0.225 \\
\hline Dec & 1015.58 & -1.189 & -0.165 & 0.070 & -0.005 & 0.031 & 0.001 & 0.962 & 0.950 & 0.280 \\
\hline
\end{tabular}

March, where it then increases till July and then decreases slowly toward November, and then rises in December. The maximum pressure value of about $1012.799 \mathrm{~Pa}$ occurred in July and the minimum of about 1008.695 Pa occurred in March.

Tables 3, 4 and 5 show the multiple regression analysis results using the polynomial approach for temperature relative humidity and pressure, respectively. For example in Table 3, the coefficient of determination $\left(R^{2}\right)$ for temperature in the dry months (November, December, January, February, and March) ranges between 0.788 and 0.909 while those of wet months range between 0.921 and 0.974 . This shows that the wet months experience a better correlation than the dry months. The result agrees with the work of Rodriquez-Lado et al. [14] conducted in Paulo (Brazil); that in the dry months (for Brazil it is May to August), the $\mathrm{R}^{2}$ is usually low because the temperature is usually extreme. The result suggests that the coefficients $b_{0}$ to $b_{6}$ in Table 3 can be used to determine the temperature of a location with the known longitude, latitude, and elevation using Eq. (8).

Table 4 presents the result of multiple regression analysis of relative humidity. It can be seen that the dry months have the lowest values of $R^{2}$ and also with the highest value of standard error. SE for the dry months is between 4.9857 in November and 10.1123 in January. The results 
also show that August has the lowest $R^{2}$ value of 0.7073 and the lowest SE value of 1.0302. The implication is that the $\mathrm{RH}$ value can easily be predicted using Eq. (8) in August by substituting the appropriate coefficients. The high SE values in the dry months signify the variability of $\mathrm{RH}$ across Nigeria and the difficulty in predicting of $\mathrm{RH}$ values of some locations around this period. Also, Table 5 shows the regression result for pressure, and $R^{2}$ was observed to be high for rainy months. February and November have the lowest value of about 0.8455 and 0.8146 , respectively. This shows that the pressure over Nigeria within this period fluctuates and the prediction to very high accuracy may be difficult.

Figure 3 shows the spatial distribution pattern of temperature using the interpolation techniques by Kriging and IDW for January. The month of January is significant in dry

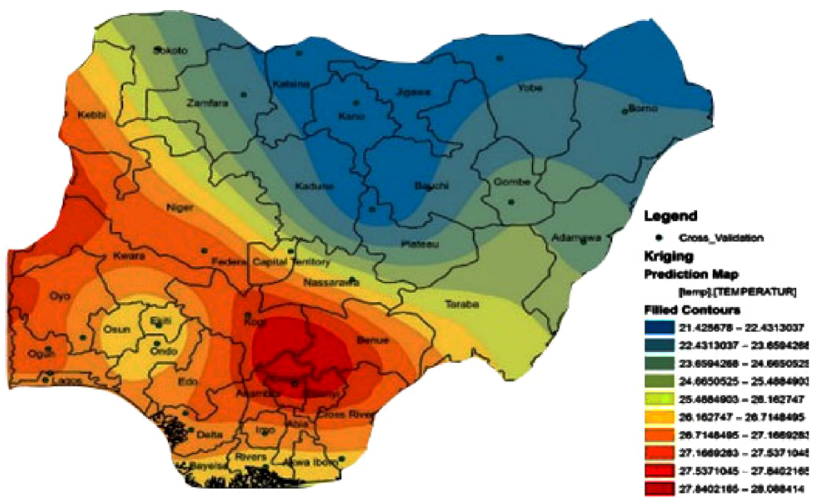

(a) seasonal months, hence the choice of January. The kriging interpolation approach shows a spatial map with a smooth and gradual regular pattern than the IDW technique. It can be observed from Fig. 3 that the spatial pattern of temperature interpolated by Kriging and IDW in this month shows a gradual decrease from south to north and from west to east. This can be due to northeastern winds that travel and transport dust particles from the Sahara Desert and usually move from north to the southern part of Nigeria during dry seasonal months (November-March). However, Fig. 4 shows a spatial pattern for July which is a significant month in wet seasonal months (April-October). The kriging and IDW spatial pattern showed the temperature values with a gradual decrease from north to south and from west to east. This is because the moist south-western winds from the South Atlantic Ocean are predominant

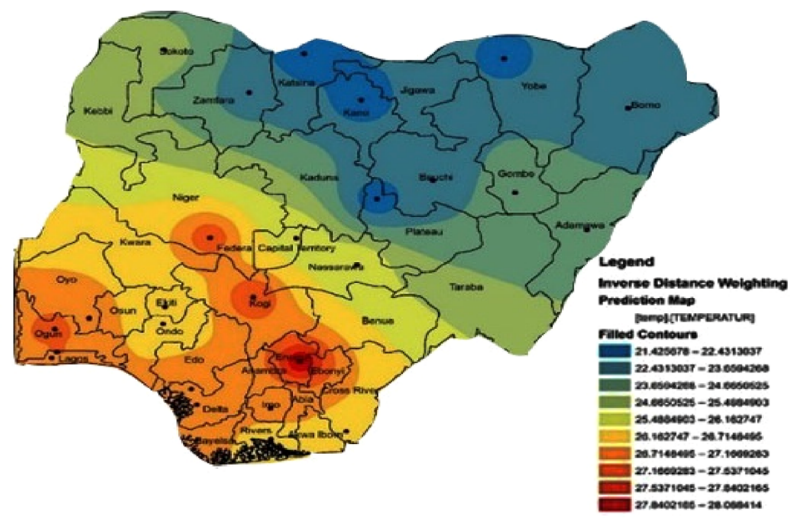

(b)

Fig. 3 Spatial distribution of temperature for the month of January as interpolated using a Kriging b IDW

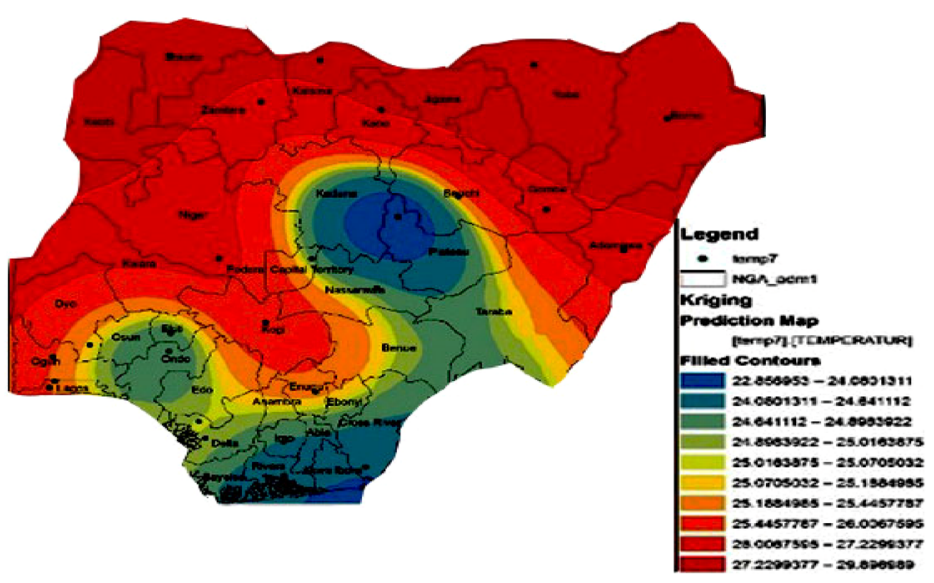

(a)

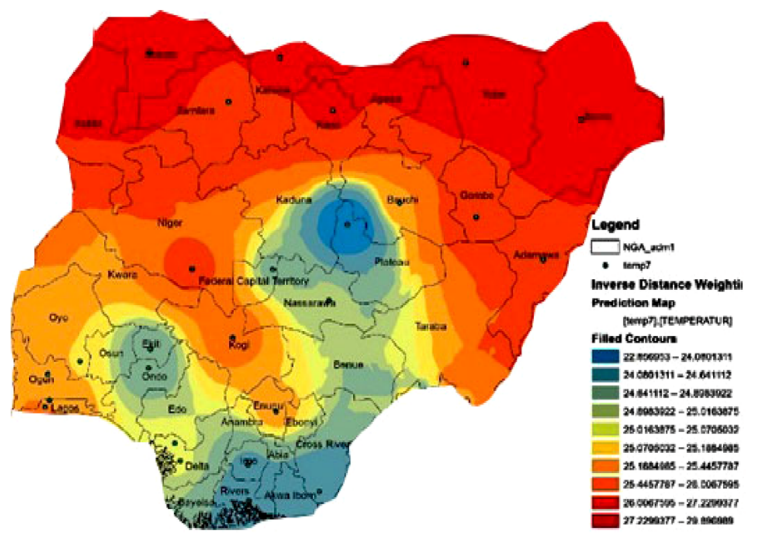

(b)

Fig. 4 Spatial distribution of Pressure for the month of January as interpolated using a Kriging $\mathbf{b}$ IDW 


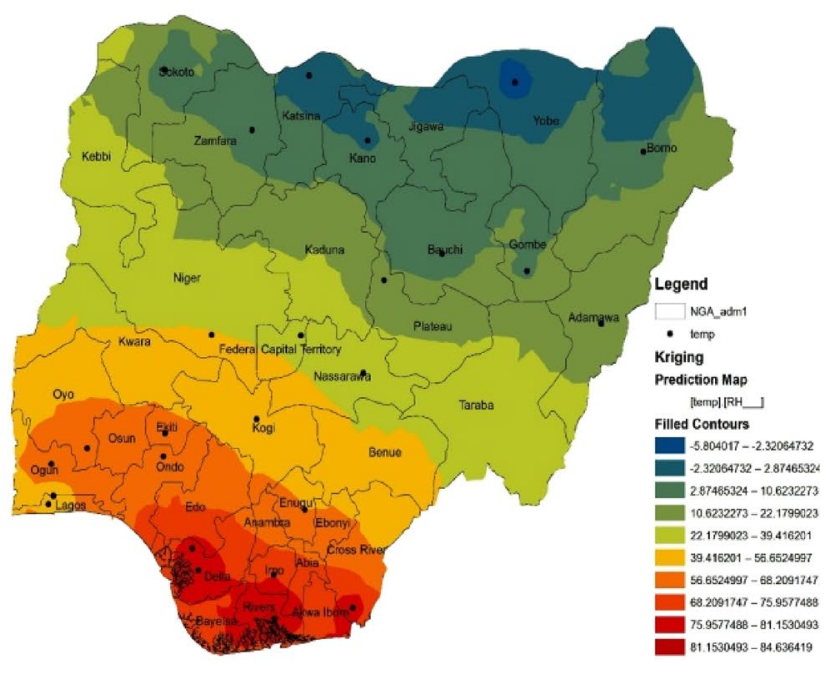

(a)

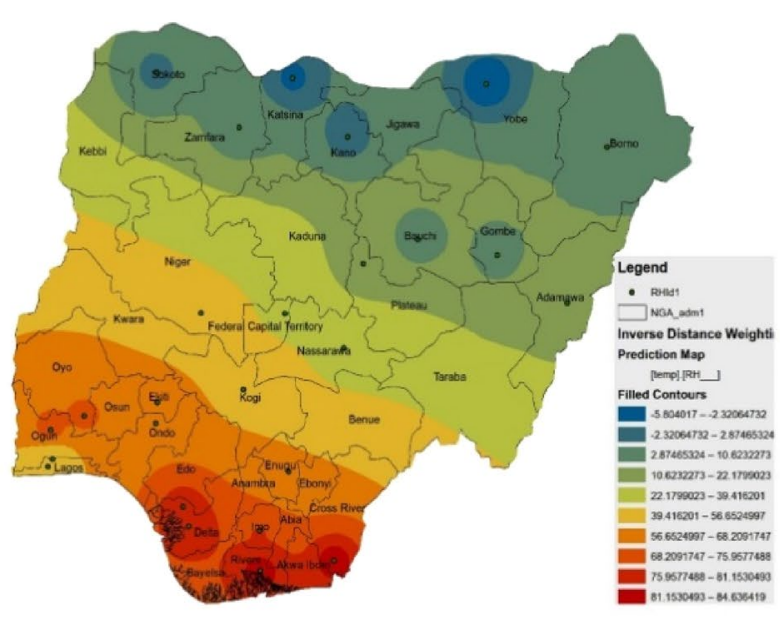

(b)

Fig. 5 Spatial distribution of temperature for the month of July as interpolated using a Kriging b IDW

over the country during the wet seasonal months. The result agrees with that of Su-Na et al. [4]. Also, the spatial relative humidity distribution for January interpolated by Kriging and IDW resulted in a diverse spatial pattern as shown in Fig. 5. Some of the negative values of relative humidity in Fig. 5 are due to the extremely high-temperature values in the concerned areas, particularly during the intense dry seasonal months like January. The Kriging techniques showed more gradual and smoothing changes than IDW as earlier reported in the work of [15] and [16]. In both of the interpolation techniques, the relative humidity was found to be high in the Coastal, Guinea Savannah, and the Mid-land regions. The month of July (Fig. 6) follows the same pattern of spatial distribution. The relative humidity values were found to be low in the Sub-Sahelian region as depicted in Fig. 7. This is due to high-temperature values in the Sub-Sahelian and the low-temperature values in the other three regions along the southern part of Nigeria. It can be observed that the locations with high elevation values have low relative humidity over Nigeria. Figures 8 and 6 show the interpolation techniques of pressure by Kriging and IDW for January and July which also represent

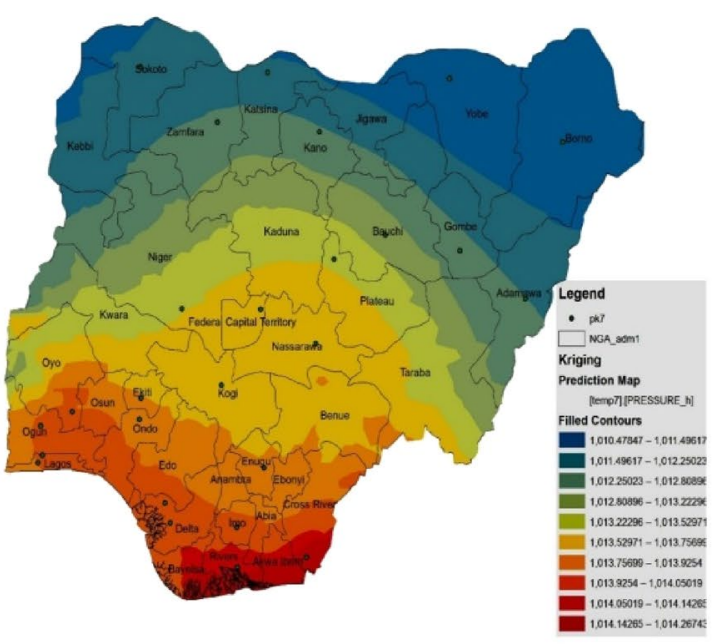

(a)

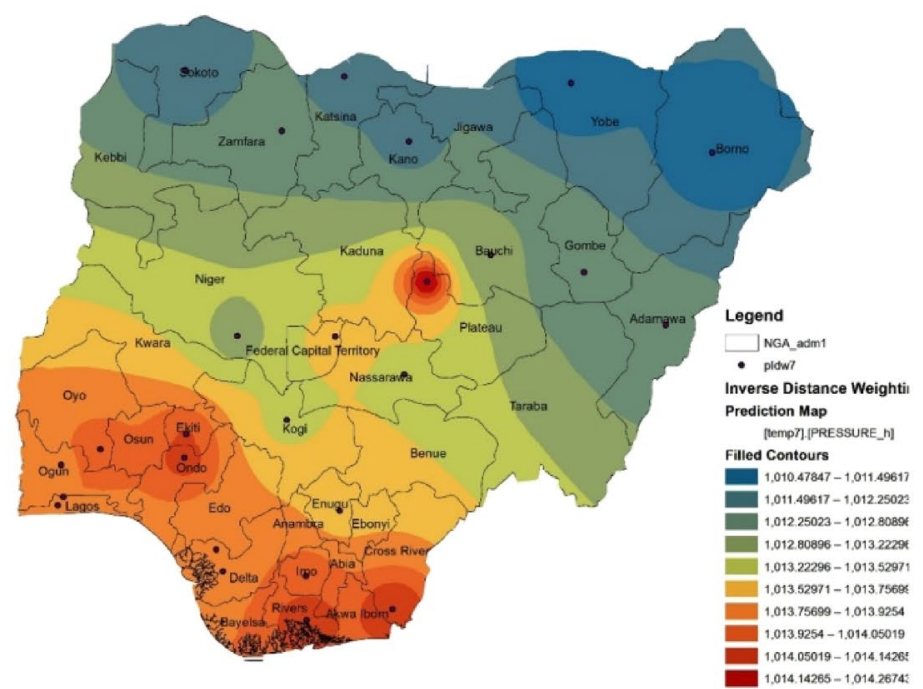

(b)

Fig. 6 Spatial distribution of pressure for the month of July interpolated by a Kriging $\mathbf{b}$ IDW 


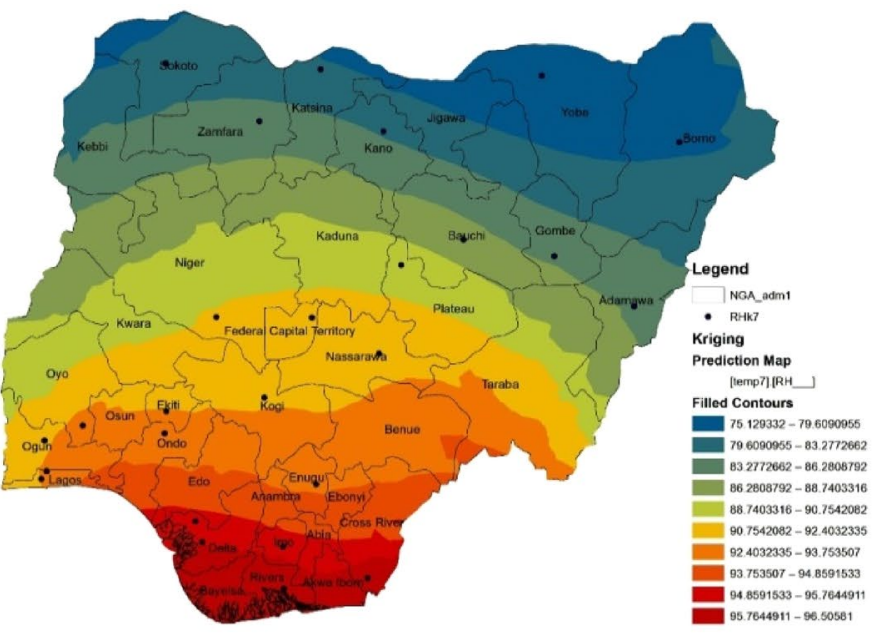

(a)

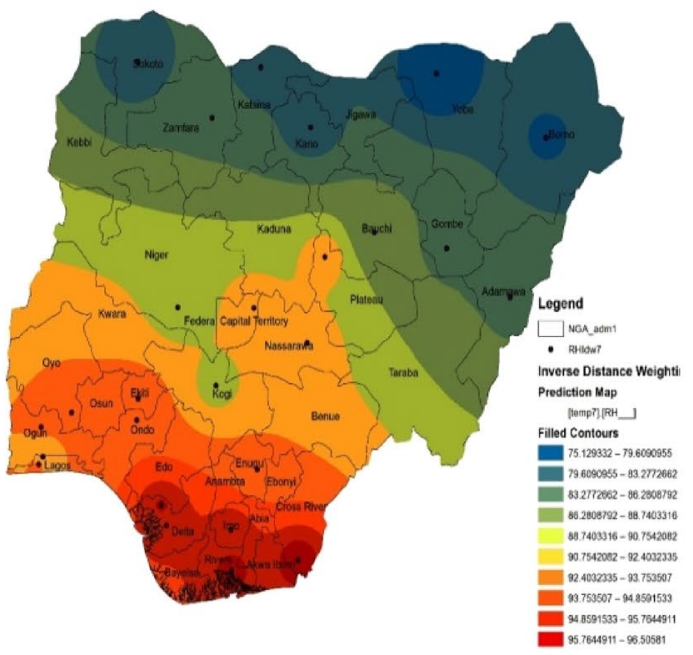

(b)

Fig. 7 Spatial distribution of relative humidity for the month of July as interpolated using a Kriging b IDW

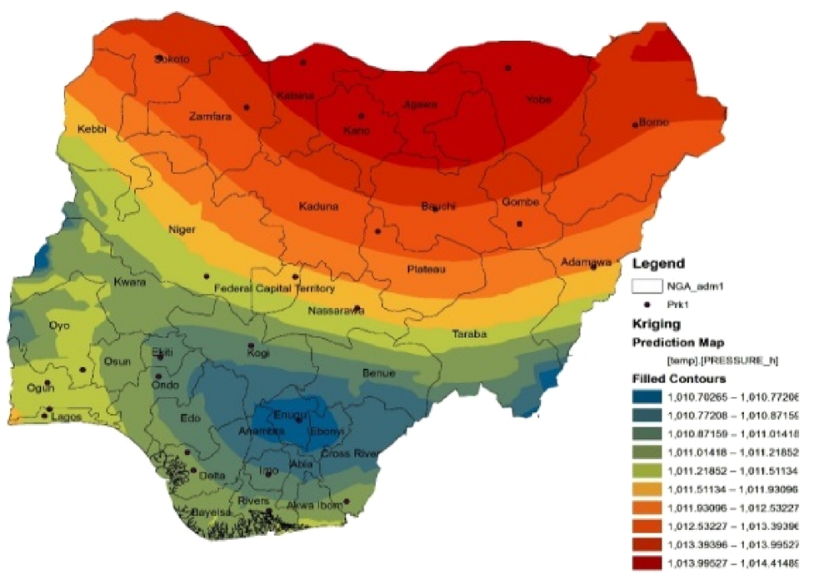

(a)

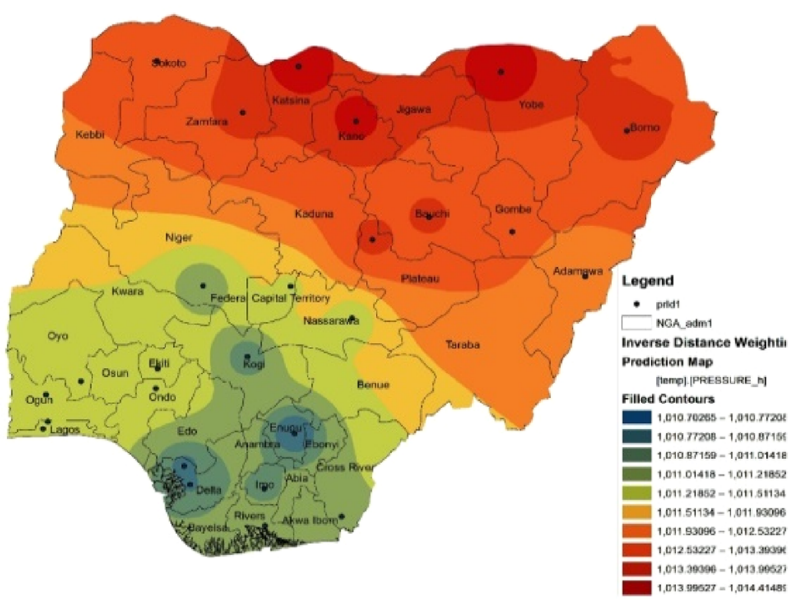

(b)

Fig. 8 Spatial distribution of relative humidity for the month of January as interpolated using a Kriging b IDW

the dry and wet seasonal months, respectively. The values of atmospheric pressure are high in the northern part of the country and reduce gradually towards the southern part of the country as shown in Fig. 8 for January. However, atmospheric pressure in July was found to be high in the southern part of Nigeria and decreases gradually towards the northern parts as shown in Fig. 6. This is due to the high climate mechanism as a reversal of air-currents which causes the change in pressure with high values in dry seasons and low values in wet seasonal months especially July. The Kriging interpolation approach also has a smooth and regular pattern spatial distribution than IDW in the case of pressure.

Figure 9 shows the metric system for comparing the three modeling techniques (multiple regression analysisMRA, Kriging, IDW) used in this study. Figure 9a reveals that multiple regressions have a higher coefficient of determination $R^{2}$ than kriging and IDW. Multiple regression analysis has lower RMSE and MAE than both kriging and IDW as presented in Fig. $9 \mathrm{~b}$ and c, respectively. Based on the fact that multiple regression analysis has a higher value of $R^{2}$ and lower values for both RMSE and MAE as compared with Kriging and IDW suggests that it gives a 


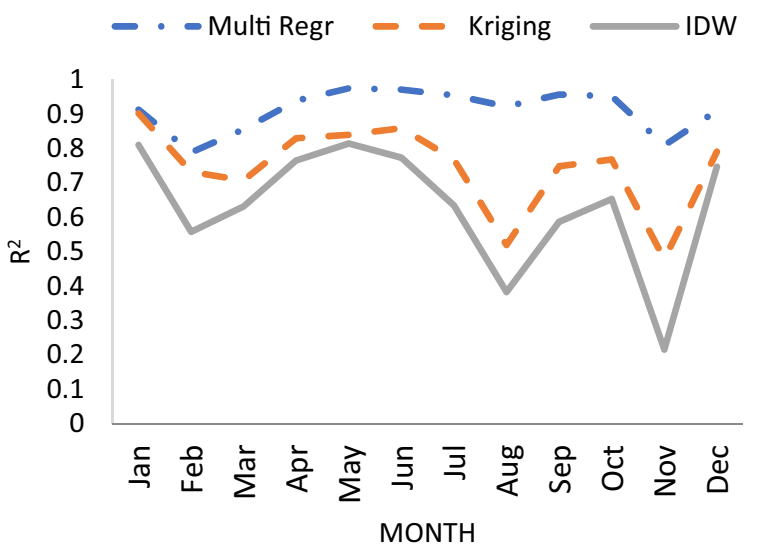

(a)
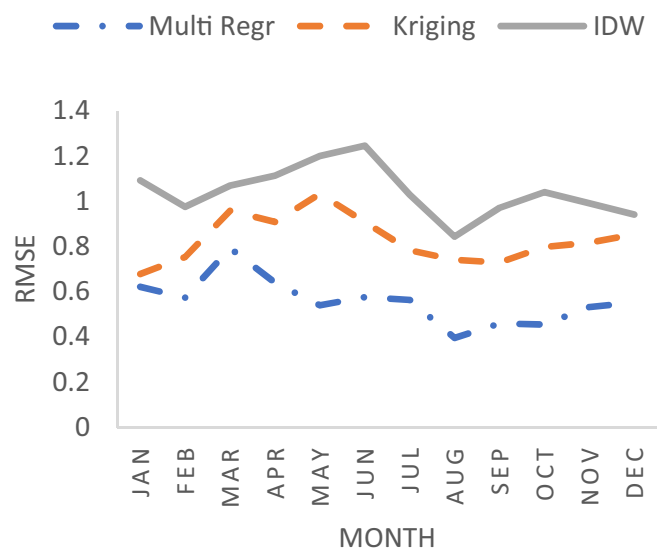

(b)

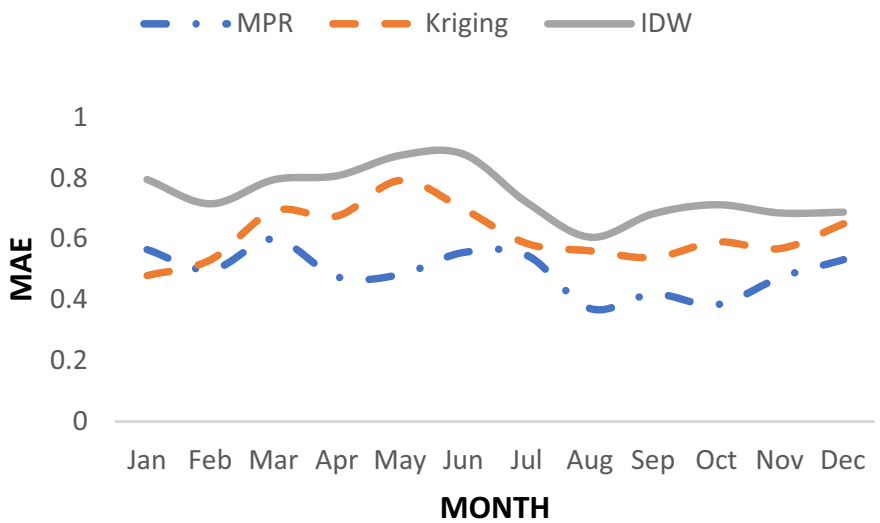

(c)

Fig. 9 Statistical comparison of the three modeling techniques for temperature: a coefficient of determination $\mathbf{b}$ root mean square error $\mathbf{c}$ Mean absolute error

Table 6 Average metric measurements of the three models for the climatic parameters

\begin{tabular}{lllll}
\hline MODELs & $\begin{array}{l}\text { Metric } \\
\text { parameters }\end{array}$ & Temperature & Pressure & RH \\
\hline MRA & $\mathrm{R}^{2}$ & 0.911767 & 0.961992 & 0.936158 \\
& RMSE & 0.558685 & 4.693234 & 0.266994 \\
& MAE & 0.491907 & 0.228972 & 3.837317 \\
Kriging & $\mathrm{R}^{2}$ & 0.744742 & 0.930450 & 0.810958 \\
& RMSE & 0.830360 & 4.659887 & 0.421447 \\
& MAE & 0.613539 & 0.290534 & 3.508404 \\
IDW & $\mathrm{R}^{2}$ & 0.630550 & 0.849625 & 0.718975 \\
& RMSE & 1.043147 & 9.010035 & 0.606180 \\
& MAE & 0.746700 & 0.392525 & 6.733290 \\
\hline
\end{tabular}

better prediction for primary radio-climatic variables in Nigeria. Table 6 indicates the average metric measurement for the primary radio-climatic variables. Results presented in Table 6 show that multiple regression analysis (MRA) has higher $\mathrm{R}^{2}$ for each variable as compared to Kriging and IDW. MRA also has lower RMSE and MAE than kriging and IDW based on temperature and pressure values. However, multiple regression analysis has a higher MAE value than Kriging for relative humidity. Generally, the result suggested that MRA predicts better than Kriging and IDW for the three primary radio-climatic variables which are important for radio-links budgeting. The result also agrees with that of [7], that polynomial regression has better prediction than the inverse distance weighting.

Figures 10 and 11 are presented to substantiate the claims in Table 7 by presenting the predicted and the observed climatic variables. Predicted temperature values can be noticed to correlate strongly to the observed values in July than January for the three prediction methods (Fig. 10a, 11a). The predicted values from the multiple regressions do not just show a strong correlation pattern but also have correlation coefficients that are higher than the commonly used interpolation methods, Kriging, and inverse distance weighting as also evident in Table 7. The 


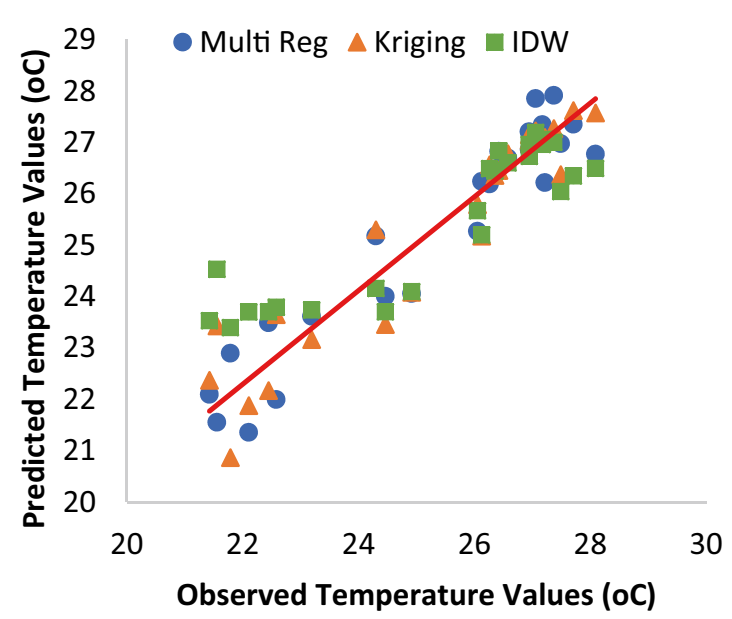

(a)

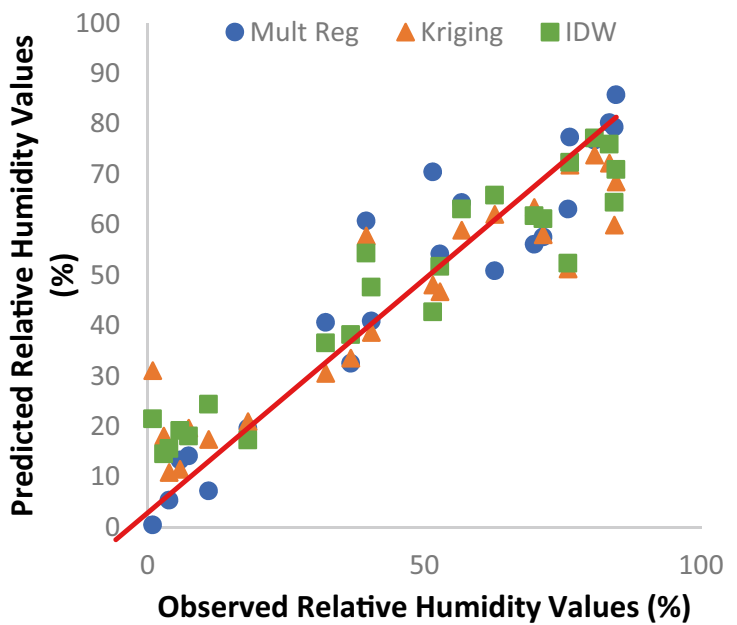

(b)

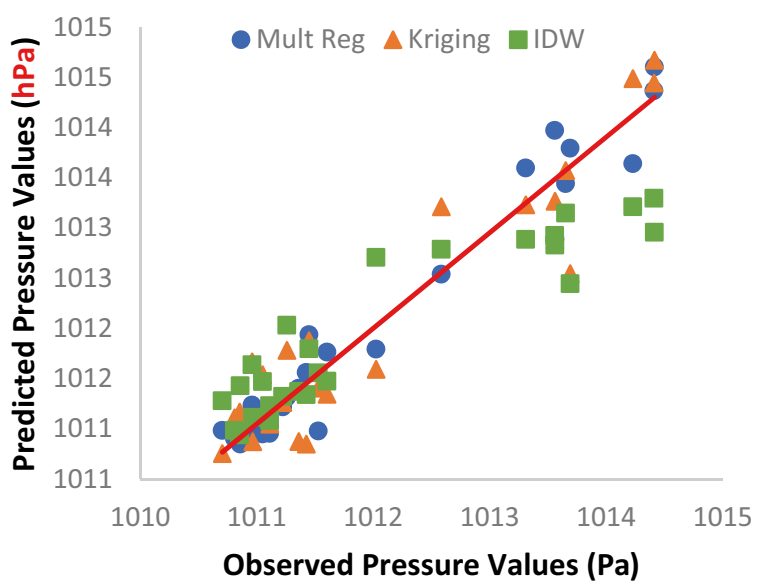

(c)

Fig. 10 Observed and predicted values of climatic variables $(n=26)$ for the month of January: a temperature b relative humidity and $\mathbf{c}$ pressure

correlation coefficient of temperature for multiple regressions for January is $1 \%$ higher than kriging and $10 \%$ higher than the inverse distance weighting (Table 7). This further suggests the high probability by which the temperature can be determined from the dependent geographical coordinate. Also, Table 7 indicates a coefficient of correlation of 0.91 and 0.95 for January and July, respectively, suggesting that the multiple regression analysis estimates temperature values accurately for the wet seasonal month (July) than the dry seasonal month (January). The RMSE of multiple regressions is lower as compared to the other two interpolation methods (Table 8). In July, the MAE of multiple regressions is 0.27 while that of kriging and IDW are 0.59 and 0.72 , respectively (Table 8 ). The relative humidity values for the plot of predicted against observed in January have even distribution around the trend line than for January. However, more predicted values of relative humidity correlate well with the observed values in July than January for the three prediction methods (Figs. 10b, $11 \mathrm{~b}$, Tables 7 and 8). The correlation coefficients for relative humidity between predicted and observed were high for the three metric measures, indicating a good prediction using geographical information (Table 7). However, the average MAEs for the three methods in January for relative humidity is $8.95 \%$ (Table 8 ), which is higher when compared with the data from other months and parameters. The predicted and observed values of pressure also correlate accurately (Figs. 10c, 11c, Tables 7 and 8) with small variability among the 26 locations of measurement. MAEs for the three prediction techniques approach an average value of approximately $0.48 \mathrm{hPa}$ (Table 8 ) for July pressure. The errors are not significant to affect the prediction results. The three approaches estimated July pressure with 


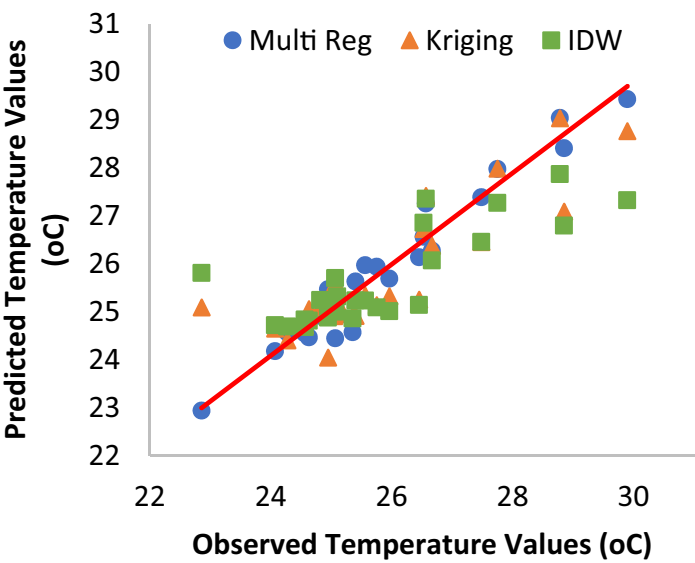

(a)

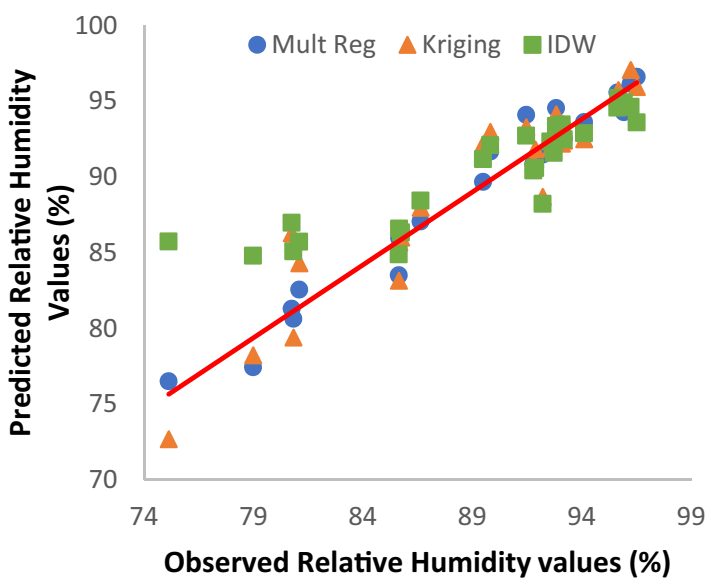

(b)

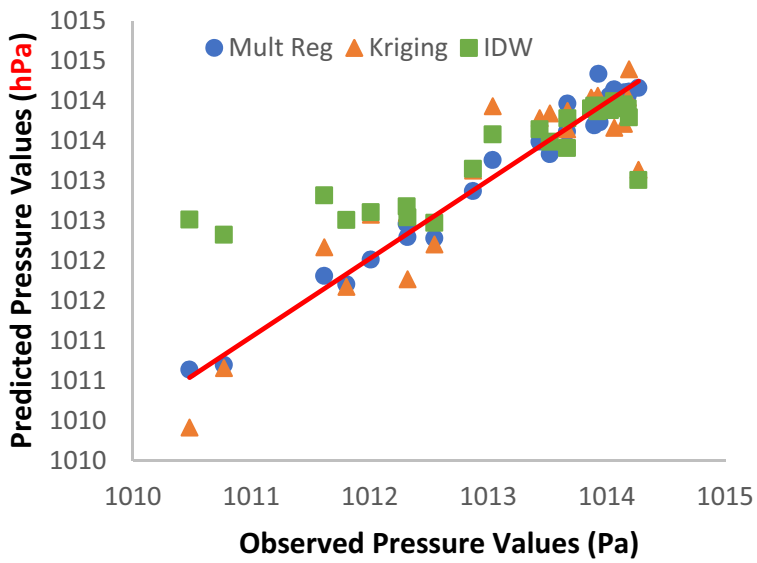

(c)

Fig. 11 Observed and predicted values of climatic variables $(n=26)$ for the month of July: a temperature $\mathbf{b}$ relative humidity and $\mathbf{c}$ pressure

Table 7 correlation coefficient between observed climate values and values predicted by the three prediction methods: Multiple regression, kriging, and inverse distance weighting. $n=26$ for temperature, relative humidity $(\mathrm{RH})$, and pressure

\begin{tabular}{|c|c|c|c|c|c|c|}
\hline & \multicolumn{2}{|c|}{ Temp } & \multicolumn{2}{|l|}{$\mathrm{RH}$} & \multicolumn{2}{|c|}{ Pressure } \\
\hline & Jan & Jul & Jan & Jul & Jan & Jul \\
\hline Multiple Regression & 0.91 & 0.95 & 0.93 & 0.96 & 0.95 & 0.98 \\
\hline Kriging & 0.90 & 0.77 & 0.90 & 0.89 & 0.89 & 0.87 \\
\hline Inverse Dist. Weighting & 0.81 & 0.63 & 0.93 & 0.81 & 0.86 & 0.76 \\
\hline
\end{tabular}

very close RMSE values and an average of about $0.56 \mathrm{hPa}$ (Table 8).

\subsection{Conclusion}

The study shows the modeling of primary radio-climatic variables using the multiple polynomial regression analysis and the result compared with other prediction methods such as Kriging and IDW based on the five years
(2013-2017) real-time data obtained from the European Centre for Medium-Range Weather Forecast (ECMWF). The result reveals that multiple regression analysis using the polynomial approach can be used to predict the temperature, relative humidity, and pressure of locations in Nigeria especially the extreme parts of the country where siting of meteorological stations may be difficult. Although the standard errors in predicting monthly climatic factors are greater for $\mathrm{RH}$ and lower for temperature and pressure, 
Table 8 Summary statistics for prediction of January and July temperature, relative humidity and pressure from multiple regression, kriging, and inverse distance weighting

\begin{tabular}{lllcccc}
\hline & Mean value ( \pm 1 SD) & RMSE & MAE & Mean value $( \pm 1$ SD) & RMSE & MAE \\
\hline Temperature $\left({ }^{\circ} \mathrm{C}, \mathrm{n}=26\right)$ & January & July & & & & \\
Observed values & $25.37 \pm 2.20$ & & & $25.85 \pm 1.63$ & & \\
Multiple regression & $25.37 \pm 2.10$ & 0.64 & 0.52 & $25.85 \pm 1.59$ & 0.34 & 0.27 \\
Kriging & $25.34 \pm 2.07$ & 0.68 & 0.48 & $25.74 \pm 1.33$ & 0.78 & 0.59 \\
Inverse Distance Weighting & $25.51 \pm 1.43$ & 1.09 & 0.80 & $25.67 \pm 0.99$ & 1.03 & 0.72 \\
Relative Humidity & January & & & July & & \\
(\%, $\mathrm{n}=$ 26) & & & & & \\
Observed values & $39.93 \pm 32.63$ & & & $89.44 \pm 6.01$ & & \\
Multiple regression & $39.93 \pm 31.41$ & 8.65 & 6.40 & $89.44 \pm 5.90$ & 1.13 & 0.89 \\
Kriging & $40.37 \pm 23.12$ & 12.60 & 9.99 & $89.53 \pm 6.07$ & 1.96 & 1.46 \\
Inverse Distance Weighting & $42.65 \pm 22.91$ & 12.30 & 10.47 & $90.33 \pm 3.56$ & 3.26 & 2.26 \\
Pressure (hPa, $\mathrm{n}=26)$ & January & & & July & & \\
Observed values & $1012.07 \pm 1.30$ & & & $1013.17 \pm 1.11$ & & \\
Multiple regression & $1012.07 \pm 1.26$ & 0.28 & 0.21 & $1013.17 \pm 1.09$ & 0.61 & 0.12 \\
Kriging & $1012.06 \pm 1.25$ & 0.42 & 0.33 & $1013.17 \pm 1.16$ & 0.41 & 0.31 \\
Inverse Distance Weighting & $1011.97 \pm 0.81$ & 0.62 & 0.47 & $1013.36 \pm 0.61$ & 0.66 & 0.41 \\
\hline
\end{tabular}

however, the result shows simple expressions that can be used in predicting the climatic variables (temperature, pressure, and relative humidity) as against the ambiguous maps used in most models available for prediction. The proposed models show a higher degree of accuracy because multiple regressions have higher $R^{2}$ and lower errors as compared to the other spatial distribution using interpolation techniques by Kriging and IDW. There are no major differences in the accuracy of multiple regression analysis and the commonly used Kriging method of spatial distribution. However, meteorological parameters (temperature, relative humidity, and pressure) are easily predicted with the multiple regression analysis to facilitate radio-climatic modeling for easy prediction of radio links. Hence, the result of the multiple regression analysis is recommended for predicting primary radio-climatic variables of locations of interest in Nigeria, especially for microwave applications.

Acknowledgements The authors wish to acknowledge the European Center for Medium-Range Weather Forecast (ECMWF) data used for this work.

\section{Compliance with ethical standards}

Conflict of interest The authors declare that they have no conflict of interest.

Open Access This article is licensed under a Creative Commons Attribution 4.0 International License, which permits use, sharing, adaptation, distribution and reproduction in any medium or format, as long as you give appropriate credit to the original author(s) and the source, provide a link to the Creative Commons licence, and indicate if changes were made. The images or other third party material in this article are included in the article's Creative Commons licence, unless indicated otherwise in a credit line to the material. If material is not included in the article's Creative Commons licence and your intended use is not permitted by statutory regulation or exceeds the permitted use, you will need to obtain permission directly from the copyright holder. To view a copy of this licence, visit http://creativecommons .org/licenses/by/4.0/.

\section{References}

1. Reinhardt K, Samimi C (2018) Comparison of different wind data interpolation methods for a region with complex terrain in Central Asia. Clim Dyn 51:3635-3652

2. Piazza AD, Conti FL, Viola F, Eccel E, Noto LV (2015) Comparative analysis of spatial interpolation methods in the mediterranean area: application to temperature in sicily. Water 7:1866-1888

3. Manene MM, Muthama, NJ, Ndetei CJ (2013) Use of polynomial fit to predict seasonal rainfall in Nairobi, Kenya. A world-Class University committed to scholarship excellence. Proceedings, $1-5$

4. Su-Na K, Woo-Kyun L, Shin K-II, Kafatos M, Seo DJ, Kwak H-B (2010) Comparison of spatial interpolation techniques for predicting climate factors in Korea. For Sci Technol 6(2):97-109

5. Appelhans T, Mwangomo E, Hardy DR, Hemp A, Nauss T (2015) Evaluating machine learning approaches for the interpolation of monthly air temperature at Mt. Kilimanjaro. Tanzania Spat Stat 14:91-113

6. Li J, Heap AD, Potter A, Daniell JJ (2011) Application of machine learning methods to spatial interpolation of environmental variables. Environ Model Softw 26:1647-1659

7. Goodale $\mathrm{CL}$, Aber JD, Ollinger SV (1998) Mapping monthly precipitation, temperature, and solar radiation for Ireland with polynomial regression and a digital elevation model. Clim Res 10(1):35-49. https://doi.org/10.3354/cr010035

8. Ostertagová E (2012) Modelling using polynomial regression. Procedia Eng 48:500-506. https://doi.org/10.1016/j.proen g.2012.09.545

9. John SS (2005) Introduction to RF propagation. John Wiley and Sons, Inc., Hoboken, New Jersey 
10. Akpootu D (2017) Estimation of Tropospheric Radio Refractivity and Its Variation with Meteorological Parameters over Ikeja, Nigeria. J Geogr, Environ Earth Sci Int 10(1):1-12

11. Hengl T (2009) A Practical Guide to Geostatistical Mapping http://spatial-analyst.net/book/

12. Deutsch CV, Journel AG (1998) Geostatistical software library and user's guide, 2nd edn. Oxford University Press, New York, Oxford, p 369

13. Akpinar S, Akpinar EK (2010) Modeling of weather data for the east Anatolia region of Turkey. J Urban Environ Eng 4(1):9-22. https://doi.org/10.4090/juee.2010.v4n1.009022

14. Rodriguez-Lado L, Sparovek G, Vidal-Torrado P, Dourado-Neto $D$, Macias-Varquez F (2007) Modelling of air temperature for the state of sao paulo. Braz. Sci. Agric. Scientia Agricola (Piracicaba Braz.) 64(5):460-467
15. Curtis DC, Clyde BS (1999) Comparing spatial distributions of rainfall derived from rain gauges and radar. J Floodplain Manag $1: 9-21$

16. Zhao C, Nan Z, Cheng G (2005) Methods for modeling of temporal and spatial distribution of air temperature at landscape scale in the southern Qilian Mountains, China. Ecol Model 189:209-220

17. Liu J, Chen H, Yang W (2009) Comparison of interpolation methods on annual mean precipitation in Hebei Province. Acta Ecol Sin 29(7):3493-3500

18. Wang J (2004) Research on spline interpolation poisedness and interpolation approach problems. Dalian university of technology, Dalian, China

Publisher's Note Springer Nature remains neutral with regard to jurisdictional claims in published maps and institutional affiliations. 